\title{
V Redealgas Workshop: biotechnology and sustainability
}

\author{
Ricardo Coutinho $^{1} \cdot$ Pio Colepicolo $^{2}$ • Eliane Marinho-Soriano ${ }^{3}$ - Estela M. Plastino ${ }^{4}$. \\ Mutue T. Fujii $^{5}$ - Valéria L. Teixeira ${ }^{6} \cdot$ Nair S. Yokoya $^{5}$ - Yocie Yoneshigue-Valentin ${ }^{7}$
}

Published online: 29 March 2017

(C) Springer Science+Business Media Dordrecht 2017

As the world population increases, the use of algae and their metabolites for different purposes and products in the pharmaceutical, medical, cosmetic, and bioenergy industries also grows, becoming imperative to take immediate actions and measures to sustainable use and preservation of the natural sources of macroalgae, mainly in developing countries. In the last few decades, the emphasis has changed from wild harvesting to the sustainable farming and cultivation of algae. The cultivation of algae allows the farmers to produce new chemicals in large scale with low environmental impact. The application of chemical compounds purified from diverse algal groups is increasing rapidly. In order to survive in a competitive environment, benthic marine algae have developed defense strategies and natural products that results in a considerable level of structural-chemical diversity. Many of these chemicals are considered to be secondary metabolites. Natural products obtained from macroalgae, such as fatty acids, steroids, carotenoids, phycocolloids, lectins, mycosporine-like amino acids, halogenated compounds, and polyketides are

Nair S. Yokoya

nyokoya@ibot.sp.gov.br

1 Instituto de Estudos do Mar Almirante Paulo Moreira, Arraial do Cabo, RJ, Brazil

2 Instituto de Química, Universidade de São Paulo, São Paulo, Brazil

3 Universidade Federal do Rio Grande do Norte, Natal, Brazil

4 Instituto de Biociências, Universidade de São Paulo, São Paulo, Brazil

5 Instituto de Botânica, Secretaria do Meio Ambiente do Estado de São Paulo, São Paulo, Brazil

6 Universidade Federal Fluminense, Niterói, Brazil

7 Universidade Federal do Rio de Janeiro, Rio de Janeiro, Brazil considered of high economic impact and great value products in different countries. In addition, considering the natural products, recent trends in drug discovery suggest algae as promising candidates to furnish novel biochemical active substances. In response to this growing research effort, Brazilian phycologists came together in a spirit of cooperation to develop a forum for discussing scientific efforts in algal biotechnology, and founded in 2005, in association with the Ministry of Science and Technology, "The Redealgas" (National Network in Biotechnology of Marine Macroalgae) which is a network focusing on the research and application of algae in different fields. The first Redealgas workshop was held in Angra dos Reis, Rio de Janeiro, Brazil. It encompassed the broad issues in algae such as sustainable mariculture, preservation of marine resources, fields of algae product application, capabilities, and implementation. Several industry sectors attended the meeting offered their perspectives and strategies of interests. During the meeting, it was agreed that Redealgas should gather biennially in order to discuss progress on the goals firstly placed.

This special issue of Journal of Applied Phycology is a collection of peer-reviewed research articles which were presented in the "V Redealgas Workshop: Biotechnology and Sustainability" held at Arraial do Cabo, Rio de Janeiro in 2015.

In this special issue, the paper by Farias et al. (doi:10.1007/ s10811-016-1018-x) describes the physiological and morphological approaches considering ecotypes and different reproductive phases of life history of Gracilaria caudata. Secondly, Carvalho et al. (doi:10.1007/s10811016-1014-1) compare the bioactivity (anti-quorum sensing and antibacterial) of the crude extract of six marine algae from upweeling region of Arraial do Cabo, Brazil, with associated microbiota versus one without bacteria, showing a promising potential inhibitory QS and antibacterial activity. A novel and 
sensitive green analytical method to estimate metal elements at low concentration in macroalgae is described by Picoloto et al. (doi:10.1007/s10811-016-1000-7). Under laboratory and field conditions, Fernandes et al. show how fertilization pulses affect the production of Gracilaria birdiae seedlings (doi:10.1007/s10811-016-0994-1). The paper of Ribeiro et al. (doi:10.1007/s10811-016-0970-9) displays the physiological responses and biofilter potential of Hypnea aspera (Rhodophyta, Gigartinales) cultivated in different availabilities of nitrate, ammonium, and phosphate. Romano et al. (doi:10.1007/s10811-016-0927-z) describe a new and sensitive method, based on liquid chromatography coupled with mass spectrometry (LC-MS/MS) detection in algae, to estimate low levels of both reduced and oxided glutathione and phytochelatin 3 and 4. Stephens et al. (doi:10.1007/ s10811-016-0925-1) isolated a diterpene from the marine brown alga Dictyota friabilis and report a potential microbicide against HIV-1 in tissue explants. Marambio et al. (doi:10.1007/s10811-016-0913-5) describe seasonal variations of the photosynthetic activity and pigment concentrations in different reproductive phases of Gigartina skottsbergii (Rhodophyta, Gigartinales) in the Magellan region, sub-Antarctic Chile. Pereira et al. (doi:10.1007/ s10811-016-0905-5) describe the extraction and purification of sterols in brown Antarctic macroalgae and their identification by liquid chromatography coupled with tandem mass spectrometry (CG/MS). Reis et al. (doi:10. 1007/s10811-016-0890-8) review and discuss why algaculture is still incipient in Brazil. Silva et al. (doi:10. 1007/s10811-016-0895-3) describe that Prasiola crispa
(Chlorophyta) neutralizes toxic effects of Bothrops jararacussu snake venom. Alves-Lima et al. (doi:10.1007/ s10811-016-0896-2) report the reference genes for transcript quantification in Gracilaria tenuistipitata under drought stress. Barros et al. (doi:10.1007/s10811-016-08659) describe the therapeutic efficacy in BALB/C mice of extract from marine alga Canistrocarpus cervicornis (Phaeophyceae) against Herpes simplex virus type 1. Marinho-Soriano (doi: 10.1007/s10811-016-0866-8) shows an historical context of commercial exploitation of seaweeds in Brazil. And, finally, Santos et al. (doi:10.1007/s10811-016-1034-x) describe and quantify the polyunsaturated fatty acids (PUFA) of the Antarctic red macroalgae species Iridaea cordata, Palmaria decipiens, Plocamium cartilagineum, and Pyropia endiviifolia applying CG/MS as analytical tool. The authors suggest that the high concentration in these algae may be the source of PUFA for other organisms. Soares et al. (doi:10.1007/ s10811-016-1035-9) evaluate the effect of the water-soluble fraction (WSF) of petroleum on the photosynthesis and chemical defenses of two sympatric members of the brown algal family Dictyotaceae, and Dictyota caribaea was more tolerant than Stypopodium zonale.

This special issue provides a scenario of the present status of algal biotechnology within the scope of Redealgas, which gratefully acknowledges the Editor in Chief, Prof. Michael A. Borowitzka, assistant editors, and members of editorial board of Journal of Applied Phycology. The guest editors of the special issue wish to thank all the referees for their prompt replies, advice, and valuable contribution. 